\section{THE MEMBERS OF THE ROYAL COLLEGE OF SURGEONS.}

\section{STEELE $v$. SAvory.}

SIR,-We beg to forward herewith a second list of subscriptions to the "Steele $v$. Savory Fund," which includes several amounts previously omitted. We desire to explain, in answer to inquiries, that the subscriptions now being acknowledged are those only which have been sent to the Treasurer of the Special Committee appointed in February last after the termination of the action. A "Guarantee Fund" was established on the commencement of the proceedings three years ago, towards which about $£ 250$ was received (some further contributions to this fund, promised but not then paid, have since been sent to the Special Committee and included in their first list). This amount was all expended during the progress of the action, but is allowed for in the bill of costs now delivered, from which it will be deducted.

It will be seen that there is still a balance of about $£ 1,000$ required, which would be easily obtained if every Member who has hitherto taken an interest in College reform were to send a few shillings. We should like to take this opportunity of reminding our numerous Local Secretaries of the letter which we recently sent them, and we trust that they are acting upon it. We shall also be glad if those members of our Association who have not yet paid their arrears of subscriptions will do so forthwith; we hope that these gentlemen will not put us to unnecessary trouble by delaying their remittances.-We are etc., JABEZ HoGG,

\section{W. G. Dickinson}

Joint Honorary Secretaries.

(SECOND LIST OF SUBSCRIPTIONS.)

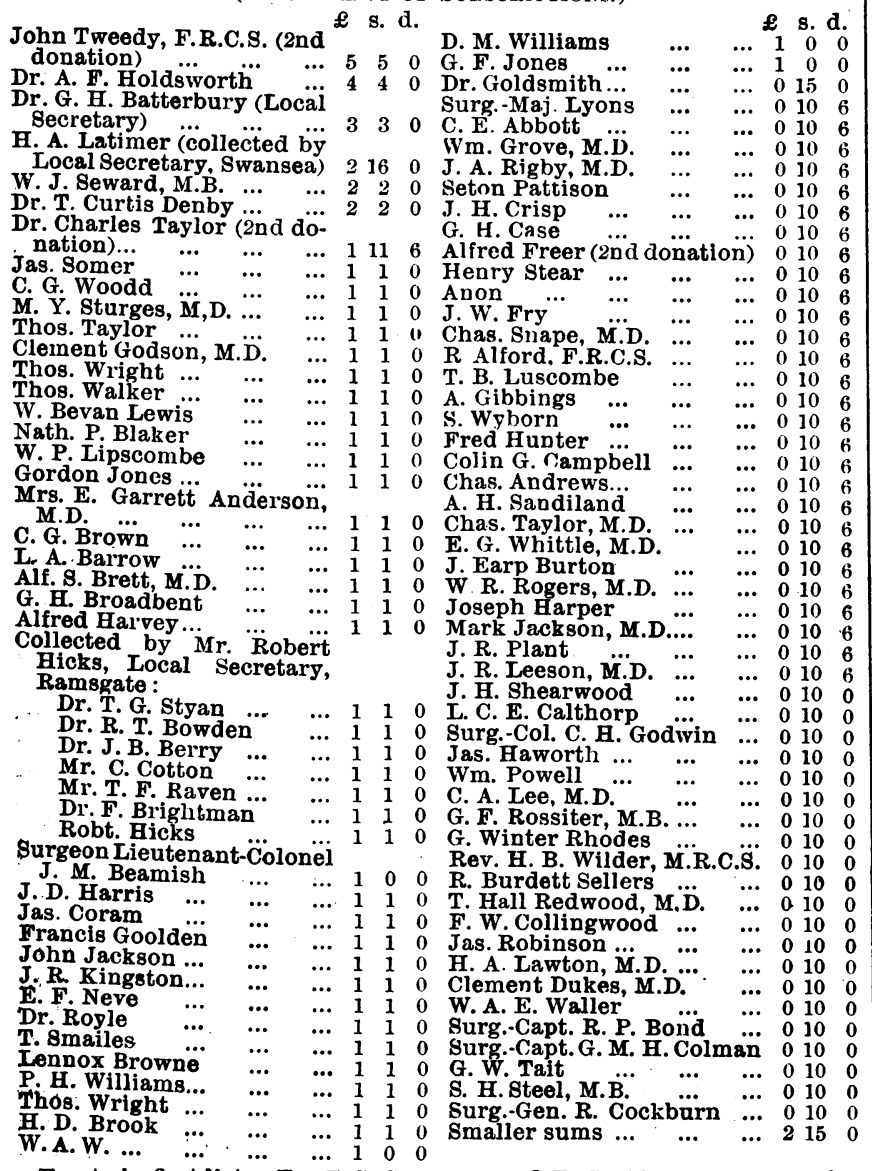

Errata in first list; - For T. S. Grenson read T. S. Gimson, £1 10s.; for Edwin H. Roe read Surg.-Maj. Roe, \&2 2s. In Dr. Thomas's letter for "finger" read "forego."
GRANTS FOR SCIENTIFIC RESEARCH.

THz Scientific Grants Committee of the British Medical Association desire to remind members of the profession engaged in researches for the advancement of medicine and the allied sciences that they are empowered to receive applications for grants in aid of such research. Applications for sums to be granted at the next Annual Meeting should be made without delay to the General Secretary, at the Office of the Association, 429, Strand, W.C. Applications must include details of the precise character and objects of the research which is proposed.

\section{THE SANITARY CONFERENCE IN PARIS.}

THE Venice Sanitary Conference was never looked upon in this country as having arrived at conclusions which were likely to be acceptable to the British Government and to British commerce, the restrictions and detention of shipping being in excess of any such danger as could be recognised by English authorities. Hence the recent meeting in Paris of delegates on the part of France, Austria, and Great Britain. The Paris Conference has now concluded its labours, and last week a fresh convention dealing with shipping at Suez was signed by Mr. Constantine Phipps, of the British Embassy, and by Dr. Thorne Thorne on the part of Great Britain, by M. Barrère, Professor Brouardel, and Dr. Proust on behalf of France, and by Count Keufstein on behalf of Austria-Hungary; and the Government of the latter country has undertaken to submit the document for the approval of the other Governments who were represented at Venice. The changes which have been made since the meeting at Venice are substantial ones, and they relate in the main to a greatly diminished severity as regards those persons who are healthy, but who have hitherto been looked upon as contaminated because they have travelled on the same ship as one or more cholera patients.

Cholera patients are to be landed in a hospital, but no persons other than these are to be looked upon as contaminated except the nurses of the sick and those who have been in actual contact with infection, a limitation which at once reduces the restrictions to a minimum. If these people be kept on board, the vessel will be detained for a period varying from a few hours to five days according to the date of the last attack, in order to see if they sicken; but if they are landed, even this diminished detention cannot be insisted on. Vessels, such as cargo vessels, having no doctor on board, will be dealt with more according to the judgment of the doctors on the Alexandria Board, but in such cases the crew are the only individuals who will come under their control. The Convention requires that proper means of isolation are to be established at Moses's Wells near Suez, and that adequate means of disinfection are to be provided. But when steam power is available on board, the disinfection can generally be done on board, and where this is practicable, the outside limit of detention for purposes of disinfection will be twenty four hours. The full details of the modification have to be submitted to the other Powers before publication, but it is quite evident that the passage in quarantine of so-called infected vessels has been freed from many unnecessary restrictions, and that a number of useless detentions will be avoided if the several Powers concerned agree to follow the lead of England, France, and Austria.

IT is announced that Sir James Paget, Bart., has been appointed a Deputy Chairman of the Clerical, Medical, and General Life Assurance Society, in place of the late Sir William Bowman, Bart.; and that Sir Andrew Clark, Bart., President of the Royal College of Physicians, has been elected to fill the vacant directorship on the Board of the Society. 